\title{
Relationship between Electronic Conductivity of Iron Oxide-Containing Slags and Reaction Kinetics with CO-CO2
}

\author{
Mansoor Barati and Kenneth S. Coley \\ Version Post-print/Accepted Manuscript \\ Citation Barati, M. \& Coley, K. Metall and Materi Trans B (2008) 39: 147. \\ (published version) https://doi.org/10.1007/s11663-007-9107-5 \\ Publisher's statement This is a post-peer-review, pre-copyedit version of an article published \\ in Metallurgical and Materials Transactions B. The final authenticated \\ version is available online at: http://dx.doi.org/10.1007/s11663-007- \\ 9107-5
}

How to cite TSpace items

Always cite the published version, so the author(s) will receive recognition through services that track citation counts, e.g. Scopus. If you need to cite the page number of the author manuscript from TSpace because you cannot access the published version, then cite the TSpace version in addition to the published version using the permanent URI (handle) found on the record page.

This article was made openly accessible by $U$ of $T$ Faculty. Please tell us how this access benefits you. Your story matters. 


\title{
Relationship between Electronic Conductivity of Iron Oxide-containing Slags and Reaction Kinetics with $\mathrm{CO}-\mathrm{CO}_{2}$
}

\author{
Mansoor Barati ${ }^{*}$ and Kenneth S. Coley ${ }^{* *}$ \\ * Assistant Professor, University of Toronto, Department of Materials Science and Engineering \\ ** Professor, McMaster University, Department of Materials Science and Engineering
}

\begin{abstract}
The reaction rate of $\mathrm{CO}-\mathrm{CO}_{2}$ with FeOx-containing slags in its elementary steps involves charge exchange between slag and adsorbed gas species. Several studies have attempted to explain the complex dependence of reaction kinetics on slag composition and temperature by relating charge transfer properties of slag, namely electrical conductivity, to the reaction rate. It is discussed in this work that the electrical conductivity and charge transfer reaction in these slags are governed by electrons that are different in terms of their energy levels. Hence, dependence between the two could not be sought from a fundamental standpoint
\end{abstract}

The reaction between iron oxide containing melts and $\mathrm{CO}-\mathrm{CO}_{2}$ gases has received considerable attention due to its occurrence in several metal production and refining processes. The reaction in its simplest form can be written as an oxygen-exchange reaction between gas and slag, such as:

$$
2 \mathrm{FeO}+\mathrm{CO}_{2(g)}=\mathrm{Fe}_{2} \mathrm{O}_{3}+\mathrm{CO}_{(g)}
$$

A comprehensive model has recently been proposed by the authors ${ }^{[1]}$ to present the reaction rate based on a multi-step reaction mechanism as following:

$$
\begin{aligned}
& \mathrm{CO}_{2(g)}=\mathrm{CO}_{2(a d)} \\
& \mathrm{CO}_{2(a d)}+e^{-}=\mathrm{CO}_{2(a d)}^{-} \\
& \mathrm{CO}_{2(a d)}^{-}+e^{-}=\mathrm{CO}_{(a d)}+\mathrm{O}^{2-} \\
& 2 \mathrm{Fe}^{2+}=2 \mathrm{Fe}^{3+}+2 e^{-} \\
& \mathrm{CO}_{(a d)}=\mathrm{CO}_{(g)}
\end{aligned}
$$


The model has shown to be consistent with the experimental results and identifies reaction [3] as the rate controlling step of the overall reaction under different experimental conditions.

Due to the role of electrons in reaction [3], the speculation was raised that a connection may exist between the rate of oxygen exchange reaction and electronic structure of the slag, namely the electronic conductivity. In some previous studies, attempts have been made to explain the dependence of reaction rate constant on surfactants concentration ${ }^{[2]}$ and iron oxide content ${ }^{[3]}$ in relation to the dependence of slag conductivity on these parameters. The purpose of this paper is to discuss the relationship or lack thereof, between the electronic conductivity of iron oxide containing slags and their catalytic behavior

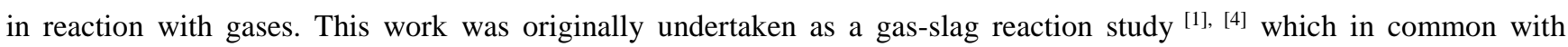
previous work by others ${ }^{[5]}{ }^{[6]}$ indicated a mechanism involving free electrons at the surface of the slag (i.e. reactions [3] and [4]). As a way to probe this mechanism further, the electronic conductivities of several slags were measured and reported ${ }^{[7]}$, ${ }^{[8]}$. The current paper attempts to bring the data on electronic conductivity and gas-slag kinetics together, and investigate any relationship between the two.

The dependence between the catalytic activity and electronic structure of semiconductors has been established for many years. ${ }^{\text {e.g. }}{ }^{[9]-[13]}$ According to Wolkenstein ${ }^{[10]}$ the reactions of gases with solid crystals can be divided into two types; the reactions whose rate are promoted by electrons are called 'Acceptor' or 'n-type'. 'Donor' or 'p-type' reactions on the other hand are those that are accelerated by electron holes. These definitions are consistent with the terms used to classify $n$ and $p$ type semiconductors, where in the former, electrons and in the latter, holes are the dominant electronic charge carriers. An acceptor reaction on the surface of a $n$-type semiconductor entails transfer of an electron from the conduction band of the crystal to the adsorbed gas, whereas the reaction with a p-type semiconductor creates a hole in the valence band of the crystal.

The relation between the reaction rate constant $(k)$ and initial electronic conductivity ${ }^{\dagger}\left(\sigma_{e}\right)$ of the semiconductor can readily be understood, if one considers the dependence of both on the concentration of the charge carriers. For example, the rate constant $(k)$ for the acceptor reaction [3], may be related to the concentration of electrons as:

$$
R=k P_{\mathrm{CO}_{2}}\left[e^{-}\right]
$$

Where $R$ is the reaction rate in mol.cm $\mathrm{cm}^{-2} \cdot \mathrm{s}^{-1}$ and $k$ is in mol.cm $\mathrm{cm}^{-2} \cdot \mathrm{s}^{-1} \cdot \mathrm{atm}^{-1}$.

From Eq. [7], the apparent rate constant may be defined as

$$
k_{a}=k\left[e^{-}\right]
$$

The electronic conductivity is also proportional to concentration of carriers in the form of:

$$
\sigma_{e}=q\left(\left[e^{-}\right] \mu_{e^{-}}+\left[h^{+}\right] \mu_{h^{+}}\right)
$$

where $q$ is the charge of an electron and $\mu$ is the mobility of free electrons or holes. For an n-type semiconductor, the role of holes in the overall electronic conductivity is negligible compared to that of electrons, therefore:

† Since the transfer of charge between a semiconductor and adsorbed gas changes the electronic conductivity (by consumption or creation of carriers inside the crystal), the relationship between $\sigma_{e}$ and $k_{a}$ can be better expressed for the initial electronic conductivity. 


$$
\sigma_{e} \approx q\left[e^{-}\right] \mu_{e^{-}}
$$

Equations [8] and [10] together present a direct dependence between the rate constant and electronic conductivity as following.

$$
k_{a} \propto \sigma_{e}
$$

Figure 1schematically shows the trends between the initial electronic conductivity and the apparent rate constant, if both were changing due to an external variable (for example, changing the equilibrium oxygen potential).

\section{$<$ Figure 1 to appear here $>>$}

Liquid iron oxide and its slags are generally regarded as p-type semiconductors. Also, based on the charge transfer reactions discussed above, dissociation of $\mathrm{CO}_{2}$ can be considered as an acceptor reaction. Therefore, it might be speculated, that an inverse relationship between the apparent rate constant for $\mathrm{CO}_{2}$ dissociation and the electronic conductivity of the slag should exist. In separate studies ${ }^{[4]}{ }^{[7]}$, the authors have examined the reaction kinetic and slag electronic properties under several experimental conditions. Figure 2 summarizes the results for the cases where both rate constant and electronic conductivity measurements have been carried out under identical experimental conditions. The figure depicts the apparent rate constant $\left(k_{a}\right)$ and electronic conductivity of slags $\left(\sigma_{e}\right)$ containing $30 \mathrm{wt}$ pct $\mathrm{FeO}$, as a function of the equilibrium oxygen potential.

\section{$<<$ Figure 2 to appear here $>>$}

It is apparent from Figure 2 that for the slag with $\mathrm{CaO} / \mathrm{SiO}_{2}$ of 1.0 and $2.0, k_{a}$ and $\sigma_{e}$ do not follow a similar dependency in the studied range of oxygen potential. For example, the electronic conductivity goes through a maximum with respect to $\mathrm{CO}_{2} / \mathrm{CO}$ whereas the reactivity monotonically decreases. For the slag with $\mathrm{CaO} / \mathrm{SiO}_{2}=0.5$, on the other hand, there appears to be an approximately opposite dependence of $k_{a}$ and $\sigma_{e}$ versus $\mathrm{CO}_{2} / \mathrm{CO}$ in the range of examined oxygen potential. However this is mainly because of limited $\mathrm{CO}_{2} / \mathrm{CO}$ range and it is expected that if the oxygen potential in the kinetic measurements had been increased to higher values, (similar to the range of $\mathrm{CO}_{2} / \mathrm{CO}$ in the conductivity measurements) it could be observed that no relationship exits between $k_{a}$ and $\sigma_{e}$ that for this slag as well. This is justified based on the findings ${ }^{[2], ~[6] ~ t h a t ~ f o r ~ d i f f e r e n t ~ s l a g s, ~ t h e ~ r a t e ~ c o n s t a n t ~ m a i n t a i n s ~ i t s ~ d e c r e a s i n g ~ t r e n d ~ w i t h ~} \mathrm{CO}_{2} / \mathrm{CO}$, in the ranges one order of magnitude larger than this study. Therefore, it is evident that the rate constant and the electronic conductivity do not follow a systematic dependency on each other. This can also be readily concluded from the dependence of $k_{a}$ and $\sigma_{e}$ on $\mathrm{Fe}^{3+} / \mathrm{Fe}^{2+}$. The two models derived by authors in the previous works ${ }^{[1],[8]}$, in accord with the experimental results ${ }^{[4], ~[7]}$, suggested different correlations for electronic conductivity and rate constant as function of $x\left(=\mathrm{Fe}^{3+} / \mathrm{Fe}^{2+}\right)$ :

$$
\sigma_{\theta} \propto \frac{x}{(1+x)^{2}}
$$




$$
k_{\alpha} \propto \frac{1}{x(1+x)^{2}}
$$

The rather unexpected independence of the electronic conductivity and the rate constant in iron oxide bearing slags can be related to the difference between the mechanism of the electronic conduction in these slags and that in typical semiconductors as follows.

For conventional semiconductors, current is carried by electrons or holes that can move freely throughout the crystal, i.e 'free' electrons in the conduction band for n-type semiconductors and 'free' holes in the valence band for p-type semiconductors. Also, the reaction of gases with these materials is controlled by the concentration of these 'free' charge carriers. Therefore, for a material that its charge carriers are dominantly free, the catalytic properties (rate of reaction with gases) can be linked to the electronic properties via the role of the free electrons or holes. This was illustrated in Figure 1 However, for the iron containing slags (and transition metal oxide slags/glasses in general), electronic conduction does not take place by free carriers and cannot be explained via the simple band theory that includes charge transport in the conduction and valence bands. It has been discussed ${ }^{[8]}$ that for such materials, the current is carried by charge hopping between two different valence ions (e.g. $\mathrm{Fe}^{2+}$ and $\mathrm{Fe}^{3+}$ ), similar to the hopping mechanism proposed by Mott ${ }^{[14]}$. Therefore, the charge carrier is not free to move across the material and its paths are limited by the concentration and distribution of the two types of ion. In the other words, the conduction mechanism in these slags takes place through the valence electron that are tied to one ion most of the time, whereas in the typical semiconductors, electron or hole is free to move at any instant. The electrons involved in the reaction are however similar for both materials, i.e. they have to be free or quasi free in order to take part in the reaction. Thus, for the iron containing slags, electrons (or holes) that participate in conduction are energetically different from the 'free' electrons that participate in the interfacial reaction between gas and the melt. As a result, a relationship between electronic conductivity and the reaction kinetics in these systems does not exist, due to different underlying mechanisms governing each phenomenon.

It is worth pointing out that although the electronic conductivity and the rate constant are not governed by similar charge

transfer mechanisms, they are both strongly affected by the iron redox equilibrium (Equations [12] and [13]). Hence, a mathematical correlation may be drawn between $k_{a}$ and $\sigma_{e}$ but it would not bear any indication of a direct fundamental relationship between the two parameters.

\section{REFERENCES}

[1] M. Barati and K.S. Coley, Metall. Mater. Trans. B, 2006, vol. 37B, pp. 61-9.

[2] S. Sun, G.R. Belton, Metall. Mater. Trans. B, 1998, vol. 29B, pp. 137-45.

[3] Y. Li and I.P. Ratchev, Metall. Mater. Trans. B, 2002, vol. 33B, pp. 651-60.

[4] M. Barati and K.S. Coley, Metall. Mater. Trans. B, 2005, vol. 36B, pp. 169-78.

[5] Y. Sasaki, Hara S., Gaskell D.R. and G.R. Belton, Metall. Trans. B, 1984, vol. 15B, pp. 563-71.

[6] S. Sun, Y. Sasaki and G.R. Belton Metall. Trans. B, 1988, vol. 19B, pp. 959-65.

[7] M. Barati and K.S. Coley, Metall. Mater. Trans. B, 2006, vol. 37B, pp. 41-9.

[8] M. Barati and K.S. Coley, Metall. Mater. Trans. B, 2006, vol. 37B, pp. 51-60.

[9] G. Parravanao, Proceedings of Symposium on Electronic Phenomena in Chemisorption and Catalysis on Semiconductors, held in Moscow, eds., K. Hauffe and T.H. Wolkenstein, 1968, pp. 111-22. 
[10] T.H. Wolkenstein, Adv. Catal. Rel. Subj., 1960, vol. XII, pp. 189-264.

[11] K. Hauffe, Adv. Catal. Rel. Subj., 1955, vol. 7, pp. 213-57

[12] G. Parravanao, Catal. Rev., 1970, vol. 4 (1), pp. 53-76.

[13] A. Dowden, J. Chem. Soc., 1950, vol. 1-2, pp. 242-65

[14] N.F. Mott, J. Non-Crystall. Sol. vol. 1, 1968, pp. 1-17
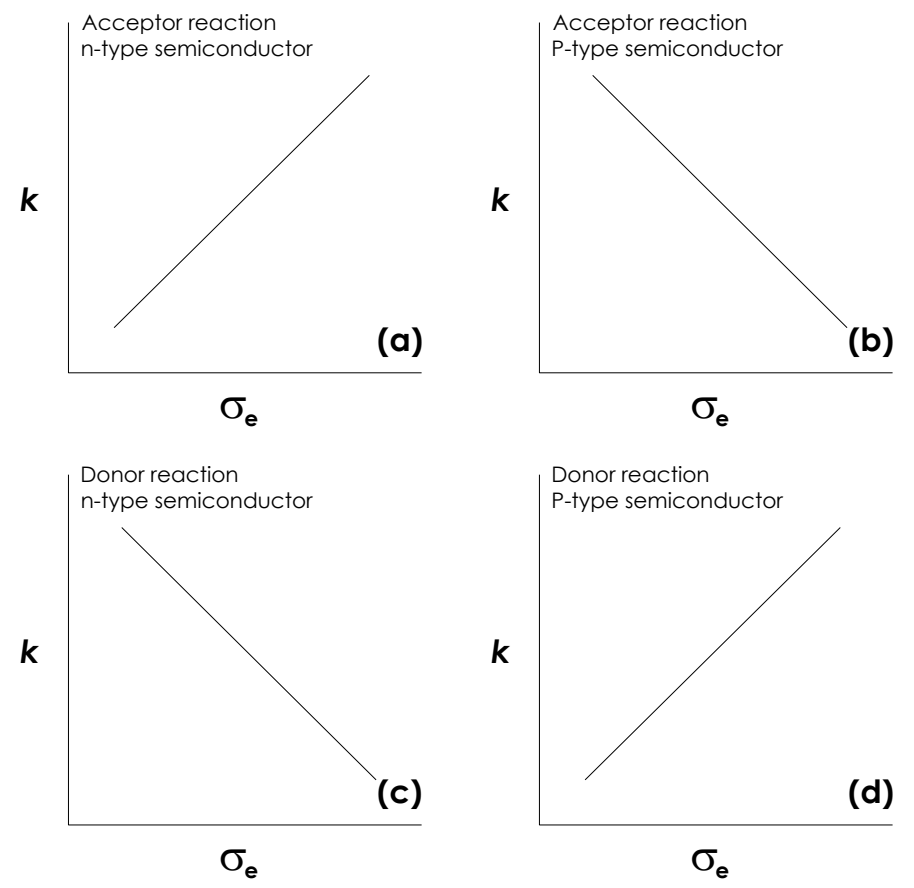

Figure 1- The schematics of relationship between electronic conductivity and catalytic activity of semiconductor. 


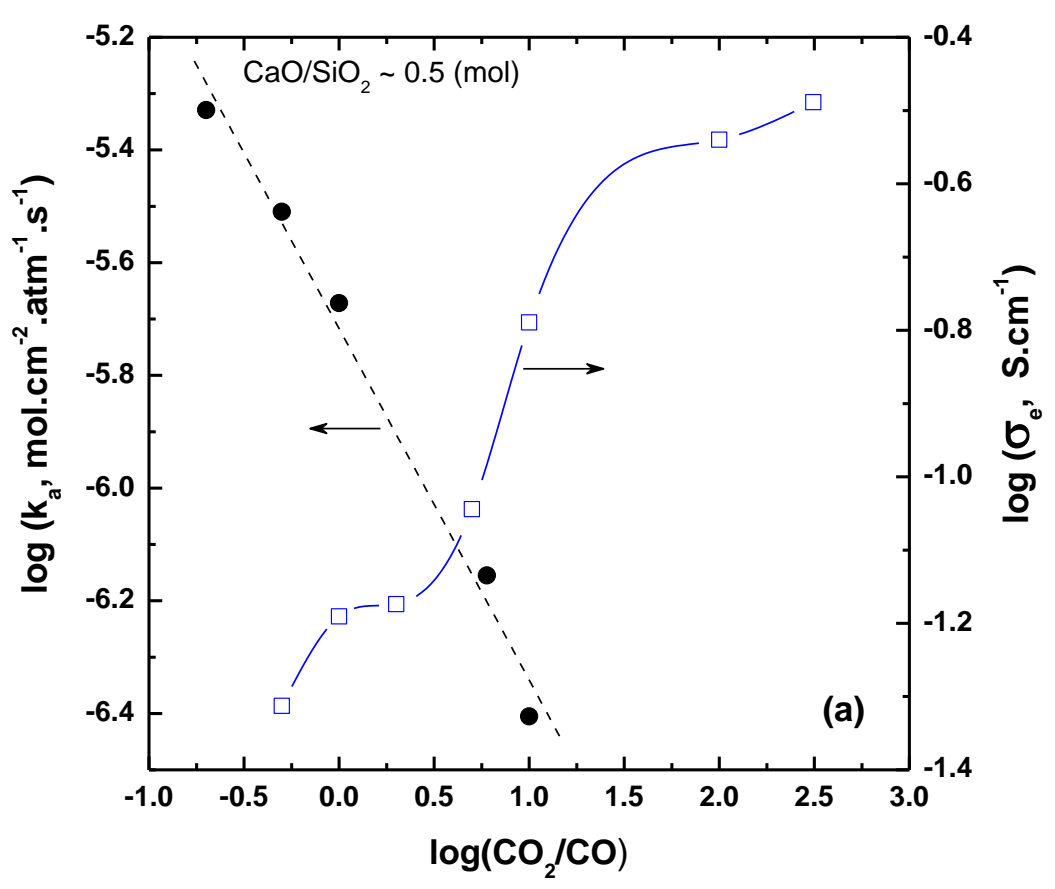

Figure 2- The apparent rate constant of $\mathrm{CO}_{2}$ dissociation on slag and the electronic conductivity of $\mathrm{CaO}_{-} \mathrm{SiO}_{2}-\mathrm{FeO}_{\mathrm{x}}$ slag as functions of the equilibrium $\mathrm{CO}_{2} / \mathrm{CO}$ ratio, (' $\mathrm{FeO}$ '= $\left.30 \mathrm{wt}, \mathrm{T}=1750-1773 \mathrm{~K}\right)$.

(Figure 2 continued on next page)

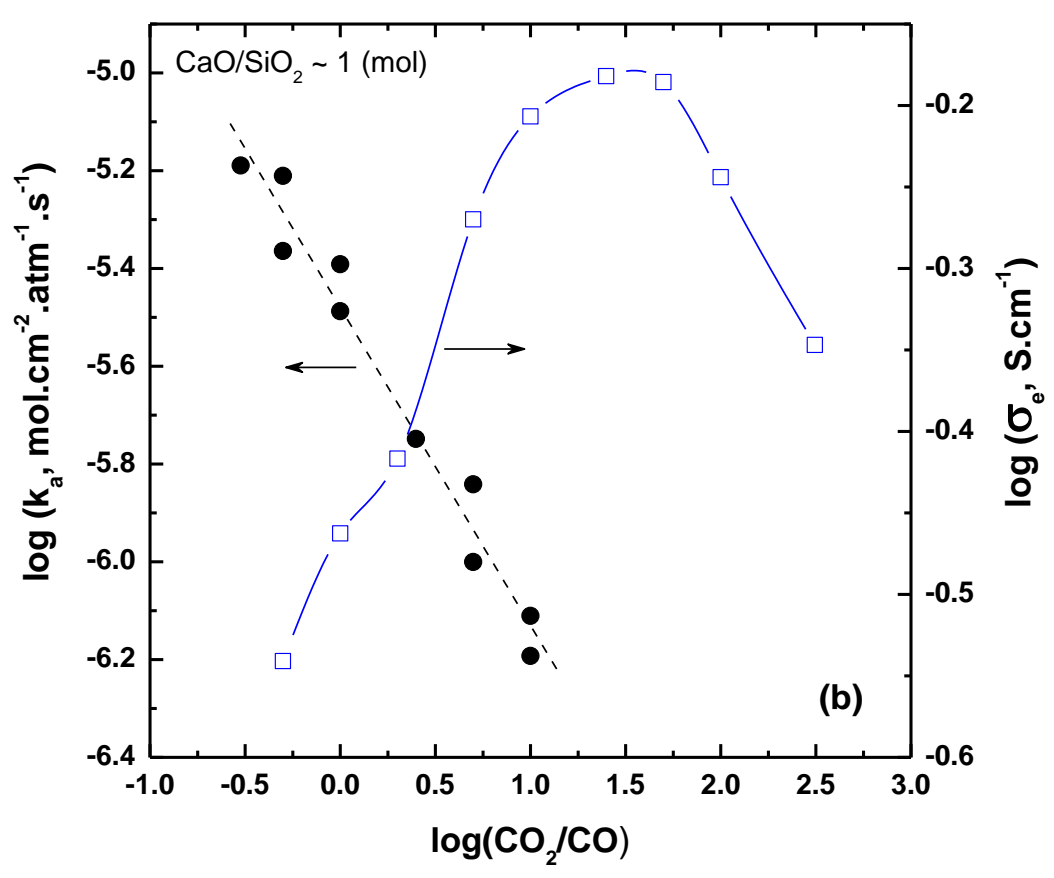




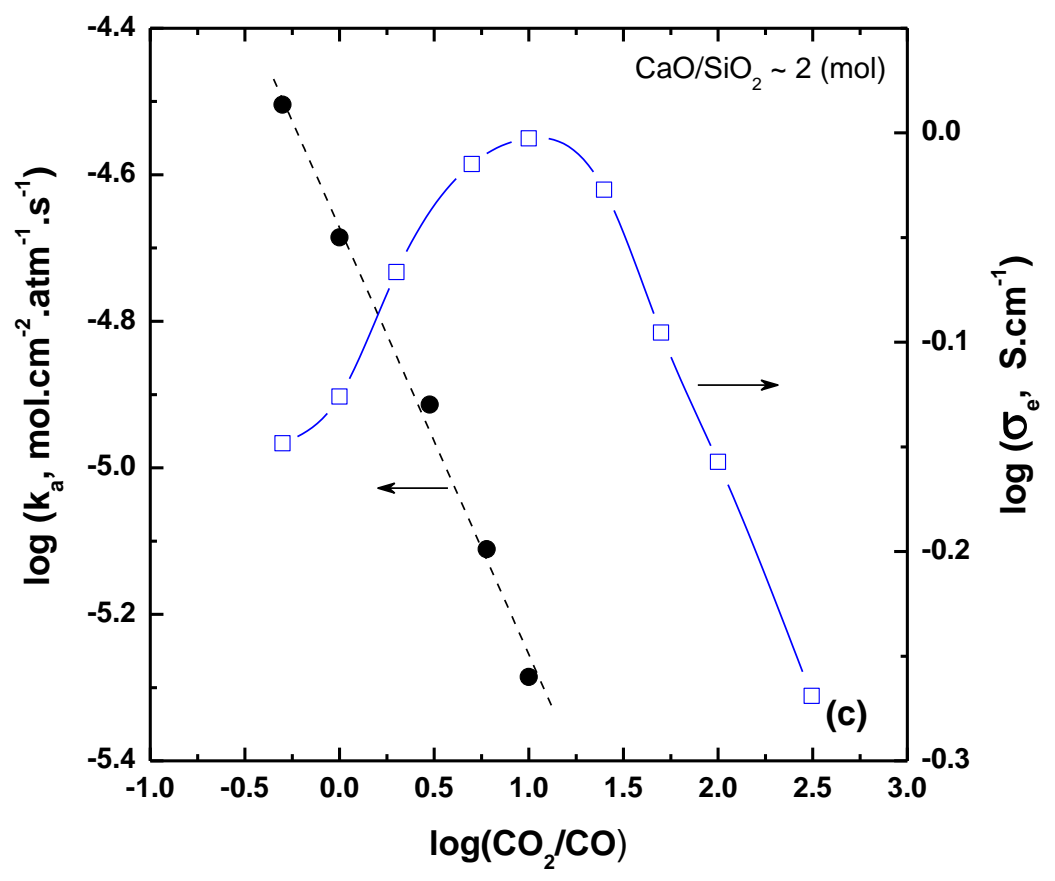

Figure 2- The apparent rate constant of $\mathrm{CO}_{2}$ dissociation on slag and the electronic conductivity of $\mathrm{CaO}_{-}-\mathrm{SiO}_{2}-\mathrm{FeO}_{\mathbf{x}}$ slag as functions of the equilibrium $\mathrm{CO}_{2} / \mathrm{CO} \mathrm{ratio},\left({ }^{\prime} \mathrm{FeO} '=30 \mathrm{wt}, \mathrm{T}=1750-1773 \mathrm{~K}\right)$. 